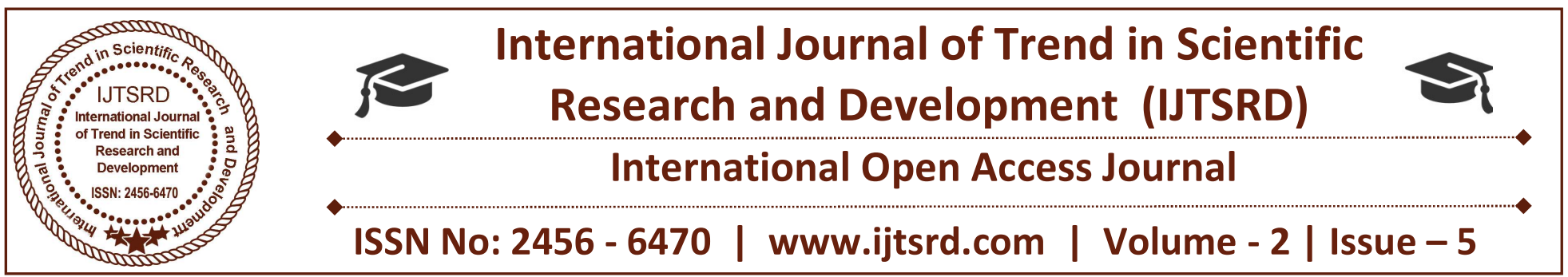

\title{
Liquid Flow Control by Using Fuzzy Logic Controller
}

\author{
Thae Thae Ei Aung, Zar Chi Soe \\ Assistant Lecturer, Department of Electronic Engineering, \\ Pyay Technological University, Pyay, Myanmar
}

\begin{abstract}
Flow measurement and control are essential in plant process control. The fuzzy logic method is very useful for such problem solving approach such as hydro power generation. In this paper, rule base and membership function based on fuzzy logic is proposed for reservoir control of dam. The rule base and membership functions have a great influence on the performance and efficiency of the plant and also to optimize the hydro power generation in the high altitude region. In this paper, the liquid level in tank and MATLAB is used to design a Fuzzy Control. The control of liquid level and flow between tanks is a basic problem in the process industries. This research used "Fuzzy Method" and "Mamdani Inference Method" to evaluate using manual "C.O.G Defuzzification" and MATLAB FIS editor validation. The purpose of this system is to design a simulation system of fuzzy logic controller for liquid level control by using simulation package which is Fuzzy Logic Toolbox and Simulink in MATLAB software. In this design two input parameters: water level and flow rate and two output parameters: release control valve and drain valve are used.
\end{abstract}

Keyword: Fuzzy logic controller, Fuzzy logic Toolbox, Flow and Level Control, Valve Control, Hydro-Electric Power Plant

\section{INTRODUCTION}

Dams were constructed for the electric power generation, flood control, irrigation system, metropolitan and industrial water supply. A good controller is vital to maintain the stability and ensure good response. Different kind of methods have been introduced and implemented to control the hydro-

electric power dam due to non-deterministic behavior of water parameters such as flow rate and release etc.

To maintain these parameters within the prescribed limits, various controls are required. Fuzzy logic controller can be modified easily to adjust the control performance of the plant. To keep the reservoir water level within predetermined ranges, control valve was adjusted for any condition. In a hydroelectric power generation project, consumers required power relied on water level and flow rate. The development of a hydro-electric power dam control system is based on fuzzy logic with two inputs and two outputs.

\section{Basic Structure of the Proposed Hydro- Electric Power Dam}

Figure 1 shows the main parts of the proposed hydro-electric power plant. The water in upper lake pass through a large pipe called penstock. Controllers are used to adjust dam lake level in set point only within shortest time by adjusting valve openness. After the control valve is $\mathrm{ON}$, the force of water spins the turbine. Inside the generator, that creates an electric field and producing electricity. Water on releasing from the dam gets to the blades of the turbine all the way through the penstock. Its slope and thickness determines the efficiency of the dam. Required power

Related water level and flow rate, the greater the vertical distance between the upper and lower lakes, the more is the generation of electricity. Water flow out of the penstock flows into the lower lake. The water is distributed for the irrigations, industries and other consumer. 


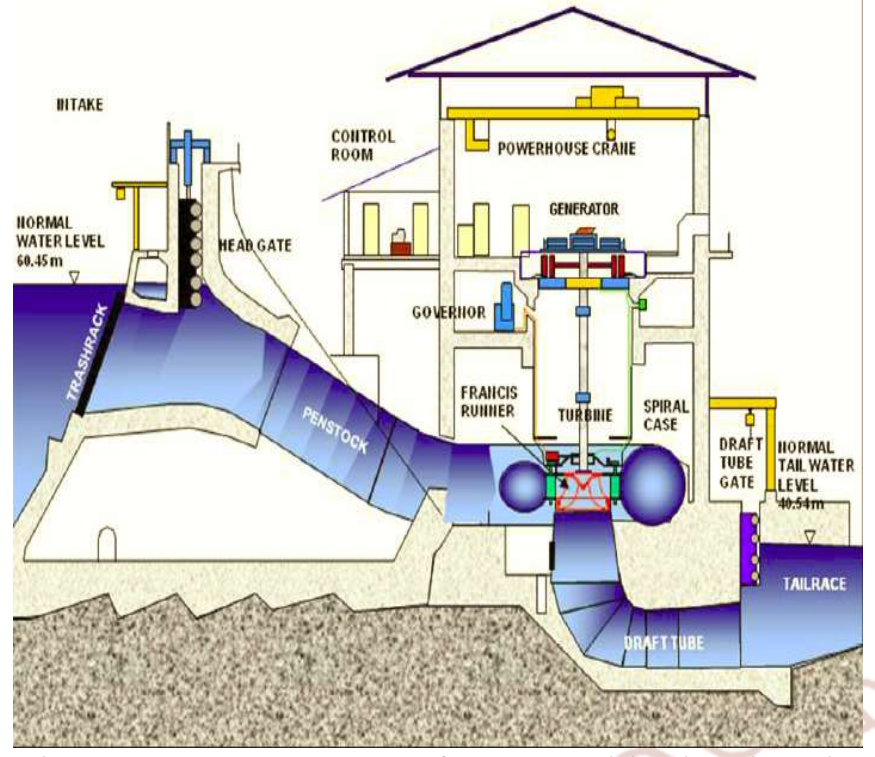

Figure.1 Arrangement of proposed hydroelectric power system

The power available is proportional to the product of head and flow rate. The general formula for any hydro system's power output is:

$$
\mathrm{P}=\eta \rho g \mathrm{QH}
$$

\section{Equation (1)}

$\mathrm{P}=$ mechanical power (Watts)

$\eta=$ hydraulic efficiency of the turbine

$\rho=$ density of water $\left(1000 \mathrm{~kg} / \mathrm{m}^{3}\right)$

$\mathrm{g}=$ acceleration due to gravity $\left(9.81 \mathrm{~m} / \mathrm{s}^{2}\right)$

$\mathrm{Q}=$ volume flow rate $\left(\mathrm{m}^{3} / \mathrm{s}\right)$

$\mathrm{H}=$ head of water across the turbine (m)

This equation is derived from the general Bernoulli equation used to estimate flow through an underflow gate:

$$
\mathrm{Q}=\mathrm{a} \mathrm{L} \mathrm{Cq} \sqrt{2 g h}
$$

\section{Equation (2)}

Where: $\mathrm{Q}=$ discharge

$\mathrm{Cq}=$ discharge coefficient

a =gate opening

$\mathrm{L}=$ gate width

$\mathrm{G}=$ gravitational constant

$\mathrm{H}=$ level

\section{Fuzzy Logic Controller}

Fuzzy Logic Controller is an attractive choice when precise mathematical formulations are not possible. There are three principal elements to a fuzzy logic controller:
a. Fuzzification module (Fuzzifier)
b. Rule base and Inference engine
c. Defuzzification module (Defuzzifier)

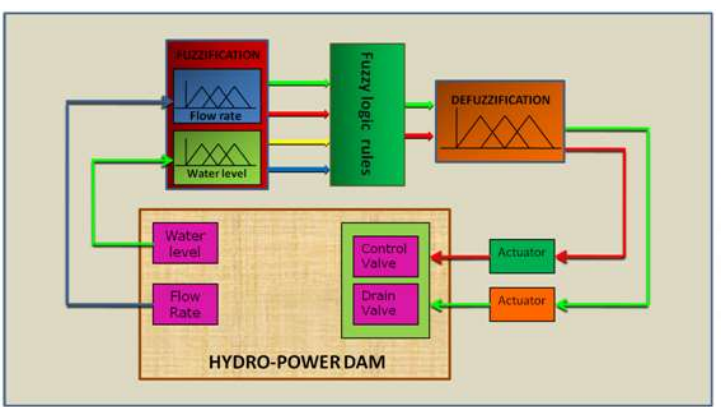

Figure.2 Block Diagram of Hydro-Electric Power Dam fuzzy control system

\section{A. Fuzzifier}

Fuzzification transforms a numerical variable (real number or crisp variable) into a linguistic variable (fuzzy number). There are two inputs parameters: water level and flow rate.

\section{B. Fuzzy Rule}

Number of active rules $=\mathbf{m}^{\mathbf{n}}$

Where $\mathrm{m}=$ maximum number of overlapped fuzzy sets and $n=$ number of inputs. For this design, $m=5$ and $n=2$, so the total number of active rules are 25 .

\section{Deffuzzifier}

Defuzzification convert Fuzzy grade to Crisp output. There are two output controller parameters: releasing control valve and drain valve.

Control Valve: The application of FLC system for dam consisting of two input variables: "Dam Lake Level" and "Water Inflow Rate". "Openness of the Control Valve" is output variable and is controlled by the FLC rule base. The main aim of this control problem is to discharge excess water (danger level or above) in shortest possible time for the overall safety of the system and thus bringing it back to safe or desired level (below danger level) through FLC.

Drain Valve: The algorithm designed for this system consists of two fuzzy input variables:" Water Level" and "Flow Rate" and one output variable "Drain Valve". The main aim of this control problem is to regulate the flow of water being fed to the turbine.

\section{FIS Editor}

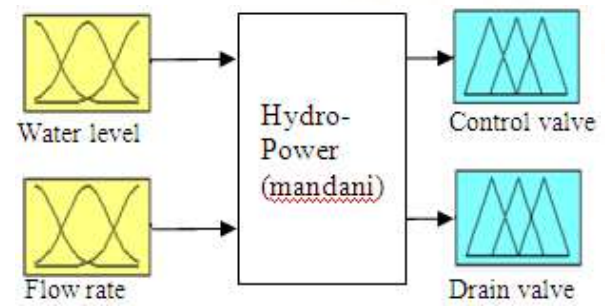

Figure .3 Mamdani type Fuzzy Controller

Fuzzy Controller has two Inputs. One is Level of the liquid in the tank defined as "level" and the other one 
is rate of change of liquid in the tank denoted as "rate". Both these inputs are applied to the Rule Editor, the controller takes the action and governs the opening of the valves which are the output of the controller and are denoted by "control valve" and "drain valve" shown in figure 3 .

\section{SOFTWARE USED}

\section{A. Matlab}

MATLAB (matrix laboratory) is a numerical computing environment and fourth-generation programming language. Developed by Math Works, MATLAB allows matrix manipulations, plotting of functions and data, implementation of algorithms, creation of user interfaces, and interfacing with programs written in other languages, including $\mathrm{C}$, $\mathrm{C}++$, Java, and Fortran.

\section{B. Software Implementation}

A continuous square wave is applied at the input to the controller. Another input to the controller came from feedback. The controller takes the action according to the error generated. This error and its derivative are applied to the controller which then the valve. The position of the valve is decided by the rule written by FLC rule editor. This system was designed and displayed the simulation of FLC for water level tank control and is shown in figure 4. Editor. According to the rules written in the Rule take the necessary action and decides the position of

Figure 5 (scope 1) shows the response of the fuzzy logic controller to the square wave input. Then the figure shows the input and output response simultaneously of the fuzzy logic controller. Yellow line shows the input and pink line shows the output. The water level can be controlled and maintained at the certain value to make sure the hydro generating unit functioning properly. Therefore, it can be concluded that the proposed control schemes are robust to disturbances acting on the system and stabilizes the water levels to the desired level.

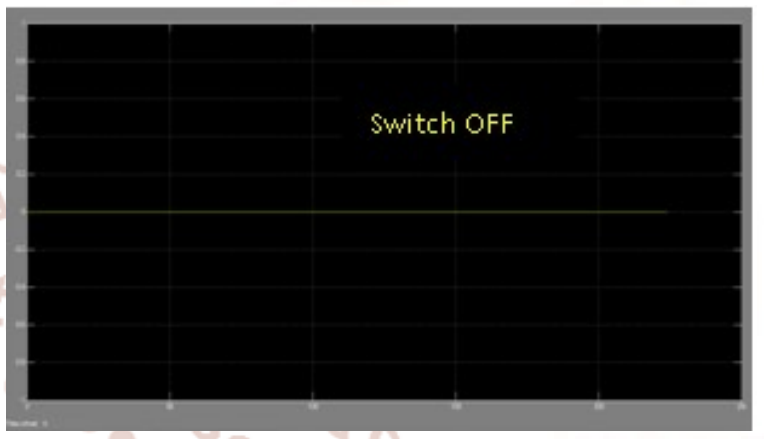

Figure.6 Sensor without overflow Limit

Figure 6 (scope 3 ) shows the sensor without overflow limit. When it has over flow, sensor switch is ON (output is 1). If is not, sensor switch is OFF (output is $0)$.

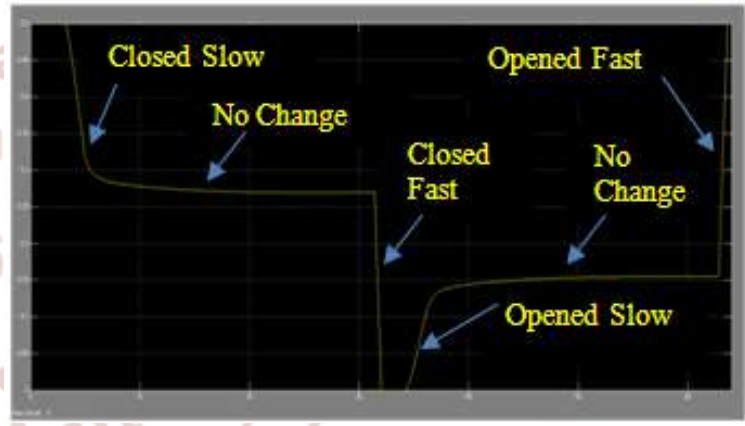

Figure .7 Openness of Control Valve

Figure 7 (scope 4) shows openness of the control

Figure .4 Simulink model by using Fuzzy Logic Controller

\section{SIMULATION RESULTS}

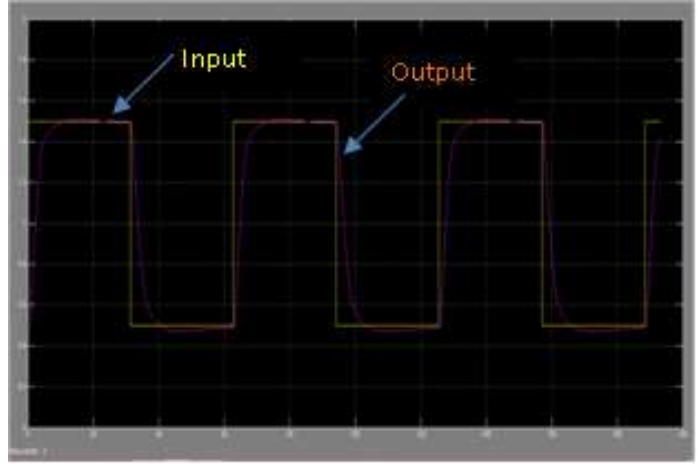

valve. In this model, maximum in flow of control valve was assigned 0.5 . The valve can be changed within the range of 0 and 0.5 . At time its reached 0.5 point is defined as fully opened and it's arrived as 0 pointed mean that as fully closed.

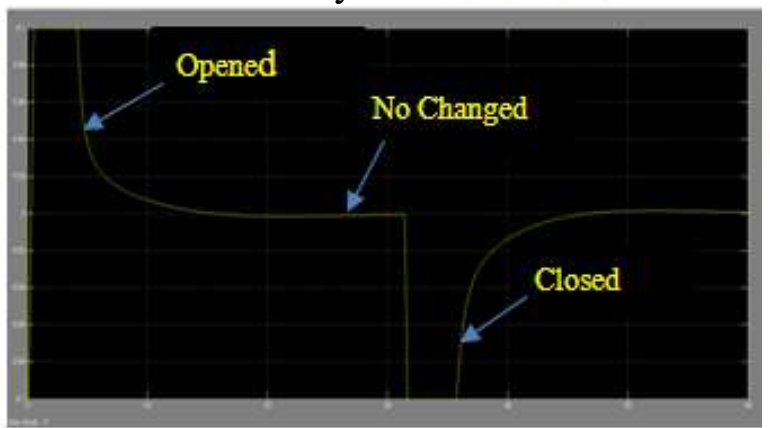

Figure .8 Performances for Fuzzy Logic Controller
Figure .5 Output Result of Water Tank System Using Fuzzy Logic Controller 
Figure 8 (scope 5) shows the performance response of Fuzzy logic controller. The performances of the controlled system are studied under variations in system parameters and in the presence of external disturbance. The simulation results indicate that the proposed control schemes work very well and are robust to change in the parameters of the system as well as to disturbance acting on the global system.

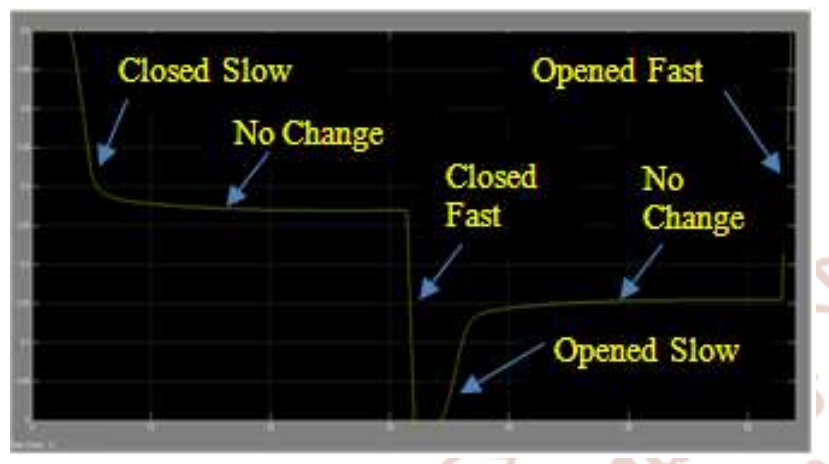

Figure.9 Openness of Drain Valve

Figure 9 (scope 6) shows the openness of drain valve. In this model, maximum in flow of drain valve was assigned 1 . The valve can be changed within the range of 0 and 1 . By the time its reached 1 point is defined as fully opened and it's arrived as 0 pointed mean that as fully closed.

\section{CONCLUSION}

Manual control of reservoir is very difficult in dam because it have nonlinear or time-variable behaviour such as sudden changes in reservoir water level. In this paper, an efficient and accurate method based on fuzzy control is proposed for hydro power generation and reservoir operating system in dam for safe and efficient performance. Hydro power dam have an important role in renewable energy resources. The aim of this control system is to keep the system within the predetermined ranges by controlling the flow through a control valve and drain valve at the dam in any condition and safely as well as efficient hydro electricity generation. In COA method, design model and simulation result are approximately the same using triangular function. By using FLC for control valve and drain valve, it has better stability for water level and flow rate.

\section{Acknowledgments}

The author would like to thank all her teachers from Department of Electronic Engineering, Mandalay Technological University, Myanmar who gave good suggestions for this research.

\section{REFERENCES}

1. Priyabrata Adhikary, Pankaj Kr Roy, Asis Mazumdar, "Safe and Efficient Control of Hydro Power Plant By Fuzzy Logic",[IJESAT] International Journal of Engineering Science \& Advanced Technology, ISSN: 2250-3676, Volume-2, Issue-5, $1270-1277$.

2. M. Abbas, M. Saleem Khan, Nasir Ali, "Fuzzy Logic Based Hydro-Electric Power Dam Control System", International Journal of Scientific \& Engineering Research Volume 2, Issue 6, June2011, ISSN 2229-5518.

3. Elangeshwaran Pathmanathan, Rosdiazli Ibrahim," Development and Implementation of Fuzzy Logic Controller for Flow Control Application," Intelligent and Advanced Systems (ICIAS), International Conference on Digital Object Identifier, pp.1-6, 2010

4. Ms. Neelam P. Naik, "Fuzzy logic to control dam system for irrigation and flooding", Late Bhausaheb Hiray S.S. Trust's Institute of Computer Application, Government Colony, Bandra (East), Mumbai 400051.

5. User's Guide of Matlab for Fuzzy Logic Toolbox.

6. http://en.wikipedia.org/wiki/Flow_meter. 